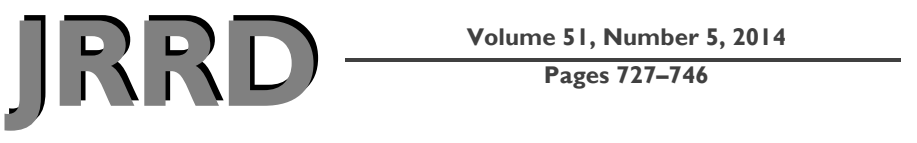

\title{
Canadian Occupational Performance Measure performance scale: Validity and responsiveness in chronic pain
}

\author{
Mieke G. Nieuwenhuizen, MSc, PT; ${ }^{1 *}$ Sonja de Groot, PhD; ${ }^{1-2}$ Thomas W. J. Janssen, PhD; ${ }^{1,3}$ Lia C. C. van der \\ Maas, MSc; ${ }^{1,4}$ Heleen Beckerman, PhD $^{3,5}$ \\ ${ }^{1}$ Amsterdam Rehabilitation Research Center | Reade, Amsterdam, the Netherlands; ${ }^{2}$ University of Groningen, Univer- \\ sity Medical Center Groningen, Center for Human Movement Sciences, Groningen, the Netherlands; ${ }^{3}$ Faculty of \\ Human Movement Sciences, MOVE Research Institute Amsterdam, VU University, Amsterdam, the Netherlands; \\ ${ }^{4}$ School of Human Movement and Sports, University of Applied Sciences Windesheim, Zwolle, the Netherlands; \\ ${ }^{5}$ Department of Rehabilitation Medicine, EMGO Institute for Health and Care Research, VU University Medical Cen- \\ ter, Amsterdam, the Netherlands
}

\begin{abstract}
The construct validity and construct responsiveness of the performance scale of the Canadian Occupational Performance Measure (COPM) was measured in 87 newly admitted patients with chronic pain attending an outpatient rehabilitation clinic. At admission and after $12 \mathrm{wk}$, patients completed a COPM interview, the Pain Disability Index (PDI), and the RAND 36-Item Health Survey (RAND-36). We determined the construct validity of the COPM by correlations between the COPM performance scale (COPM-P), the PDI, and the RAND-36 at admission. Construct responsiveness was assessed by calculating the correlations between the change scores $(n=57)$. The COPM-P did not significantly correlate with the PDI $(r=-0.260)$ or with any subscale of the RAND-36 ( $r=-0.007$ to 0.248$)$. Only a moderate correlation was found between change scores of the COPM-P and PDI $(r=-0.380)$ and weak to moderate correlations were found between change scores of the COPM-P and the RAND-36 ( $r=-0.031$ to 0.388 ), with the higher correlations for the physical functioning, social functioning, and role limitations (physical) subscales. In patients with chronic pain attending our rehabilitation program, the COPM-P measures something different than the RAND-36 or PDI. Therefore, construct validity of the COPM-P was not confirmed by our data. We were not able to find support for the COPM-P to detect changes in occupational performance.
\end{abstract}

Key words: Canadian Occupational Performance Measure, chronic pain, clinimetrics, disability, needs assessment, occu- pational therapy, outcome assessment, patient participation, patient satisfaction, patient-centered outcome, quality of life, rehabilitation, responsiveness, validity.

\section{INTRODUCTION}

Chronic pain of moderate to severe intensity occurs in 19 percent of the adult European population [1]. People with chronic pain visiting our rehabilitation center

\footnotetext{
Abbreviations: $\mathrm{COPM}=$ Canadian Occupational Performance Measure; COPM-P = Canadian Occupational Performance Measure performance scale; COPM-S = Canadian Occupational Performance Measure satisfaction scale; DIP = Disability and Impact Profile; HR-QOL = health-related quality of life; ICF = International Classification of Functioning, Disability, and Health; IPA = Impact on Participation and Autonomy; PDI = Pain Disability Index; RAND-36 = RAND 36-Item Health Survey; RNL = Reintegration to Normal Living Index; SIP $=$ Sickness Impact Profile.

*Address all correspondence to Mieke G. Nieuwenhuizen, MSc, PT; Amsterdam Rehabilitation Research Center | Reade, PO Box 58271, 1040 HG Amsterdam, the Netherlands; +31-20-6071683. Email: m.nieuwenhuizen@reade.nl http://dx.doi.org/10.1682/JRRD.2012.12.0221
} 
report that pain seriously affects their daily activities and social and working lives and that it also has an effect on their emotional status and ability to remain independent. When there is no effective treatment option to relieve (nonspecific) pain, i.e., by operation, drug therapy, nerve block, massage, or exercise, people are often told to "learn to live with the pain" instead of seeking help to stop the pain. To help these people, multidisciplinary chronic pain rehabilitation programs have been designed, including cognitive behavioral therapy, exercise therapy, and occupational therapy [2-5]. An important goal of these programs is to enable people to reduce disability or to regain independence and improve quality of life in the presence of chronic pain [6-8]. Quality of life and functioning are two important concepts with many definitions. When we refer to quality of life in the present study, health-related quality of life (HR-QOL) is meant, which is the functional effect of a medical condition and/ or its consequent therapy upon a patient [9-10]. HR-QOL is thus subjective and multidimensional, encompassing physical and occupational function, psychological state, social interaction, and somatic sensation [9]. Functioning is the most essential dimension of HR-QOL [11-12]. It refers to physical and mental functioning and role functioning, three of eight health concepts of HR-QOL most affected by disease and treatment [13] that can be measured with the RAND 36-Item Health Survey (RAND36) [14]. Physical functioning is defined as the ability to carry out various activities that require physical capability, ranging from self-care and basic activities of daily living to more vigorous activities that require increasing degrees of mobility, strength, or endurance [15].

Quality of life and functioning correlate to the concept of occupational performance that has been defined in the Canadian Model of Occupational Performance as the ability to choose, organize, and satisfactorily perform meaningful daily activities, which are specific to the person. Occupation refers to groups of activities and tasks of everyday life, named, organized, and given value and meaning by individuals within their cultural context. Occupation is everything people do to occupy themselves, including looking after themselves (self-care), enjoying life (leisure), and contributing to the social and economic fabric of their communities (productivity) [16].

Individuals may differ in how much importance they attribute to specific occupational abilities and activities. When the patients' choice and self-evaluation are incorporated, positive treatment effects on motivation, partici- pation, and functional recovery have been found in different patient populations and clinical settings [1719]. Preferably, individualized measures sensitive to varying needs and situations should be included in pain rehabilitation. Most outcome measures used in rehabilitation, however, focus on limitations and problems in fixed activities and participation areas [17].

The Canadian Occupational Performance Measure (COPM) [20] was developed to identify and prioritize patient-specific occupational problems and evaluate changes in these problems. As such, it can be a feasible and helpful clinical tool within the therapeutic process, especially in the treatment of patients with chronic pain, which mainly focuses on improving performance and changes in participation rather than in bodily functions. In a semistructured interview, the patient is encouraged to identify those activities that he or she wants, needs, or is expected to do but cannot do or those in which the patient is not satisfied with the current performance. The COPM is a generic measure, meaning it can be used in all populations regardless of diagnosis, as long as the patients are able to reflect on their lives and activities and are able to communicate on these. In literature on the COPM, consensus exists about the feasibility of the COPM as an instrument to identify a wide range of problems in daily activities [21-27]. The identification of problems may serve as a basis for establishing targeted outcomes and planning the multidisciplinary intervention.

Besides feasibility, other clinimetric properties of the COPM have been studied in different populations (for an overview, see Table 1) [17,21-25,28-46]. In this article, we prefer to use the term clinimetrics, which is similar to psychometrics but indicating measurement in clinical research [47]. For the construct validity, the questionnaire or measure is commonly compared with the best measure(s) for the construct available or with measures for a construct that should theoretically correlate with the construct under study. Despite difficulties in analyzing validity in patient-specific measures such as the COPM without the possibility of calibrating the scales [48], no other way yet exists to reflect on validity of the COPM than to test for the a priori stated theory that the COPM would correlate with more traditional measures of functioning and quality of life. While there are no "gold standard measures" for these constructs, nearly every prior study used different indices to compare the COPM with. Nearly all these indices are fixed-item questionnaires 
Table 1.

Clinimetric studies evaluating Canadian Occupational Performance Measure (COPM), including present study.

\begin{tabular}{|c|c|c|c|c|c|}
\hline \multirow[b]{2}{*}{ Study } & \multicolumn{3}{|c|}{ Study Characteristics } & \multicolumn{2}{|c|}{ Main Results } \\
\hline & Population & $N$ & $\begin{array}{l}\text { Construct } \\
\text { Measures }\end{array}$ & Correlations & Other Results \\
\hline
\end{tabular}

\section{Validity}

Boyer et al., $2000 \quad$ Schizophrenia

[28]

Carpenter et al., 2001 Patients in pain manage-

[29]

ment program

Chan \& Lee, 1997

[30]

Orthopedic and stroke

(mean age: $64.5 \mathrm{yr}$ )

Cup et al., 2003 [17] Stroke

Dedding et al., 2004

[31]

Various diagnoses (newly

referred to OT)

Disease Activity

12 PEDI, GMFM, PDMS
105 DIP, SIP68

79 AIMS2, MHAQ, WOMAC, AUSCAN, VAS-

Spearman: All $-0.5<$ $r<0.5$. Uniscale part of WQL-I: 0.458 .

106 BAI, BDI, Oswestry, Spearman: All $-0.5<$ $r<0.5$ (range: -0.4 to 0.4). Except: COPM-P/ PSEQ at follow-up ( $r=$ $0.6)$, COPM-S/PSEQ at follow-up $(r=0.5)$. Correlation coefficients at baseline are not given for lack of statistical significance.

39 Klein-Bell ADL

Pearson: All $r<0.05$

(range: -0.16 to 0.39 ). Stronger correlations at end of treatment measurement.

26 BI, FAI, SA-SIP,

Discriminant validity. Spearman: All $-0.25<$ $r<0.25$.

Spearman: All $r<0.25$ for subscales of SIP68.

Overlay of items: $74 \%$ with DIP items, $49 \%$ with SIP68 items, 63\% with open-ended question.

Pearson: All $-0.5<r<$ Validity: $72 \%$ overlay 0.0 (range: -0.31 to $0.16)$. with AIMS2.

Change of mean outcome scores. All measures showed improvement (higher results at end of treatment than at start). 
JRRD, Volume 51, Number 5, 2014

Table 1. (cont)

Clinimetric studies evaluating Canadian Occupational Performance Measure (COPM), including present study.

\begin{tabular}{|c|c|c|c|c|c|}
\hline \multirow[b]{2}{*}{ Study } & \multicolumn{3}{|c|}{ Study Characteristics } & \multicolumn{2}{|c|}{ Main Results } \\
\hline & Population & $N$ & $\begin{array}{l}\text { Construct } \\
\text { Measures }\end{array}$ & Correlations & Other Results \\
\hline $\begin{array}{l}\text { McColl et al., } 2000 \\
\text { [22] }\end{array}$ & $\begin{array}{l}\text { Former community OT } \\
\text { clients (between } 2 \text { mo and } \\
2 \text { yr ago) }\end{array}$ & 61 & $\begin{array}{l}\text { SPSQ-Satisfaction, } \\
\text { RNL-Performance, } \\
\text { LSS, PPCL }\end{array}$ & - & $\begin{array}{l}\text { Hierarchical multiple } \\
\text { regression. Overlay with } \\
\text { PPCL for COPM-P: } \\
\text { 21\% variance explained } \\
\text { for SPSQ-Satisfaction, } \\
\text { 13.4\% variance } \\
\text { explained for RNL- } \\
\text { Performance. Overlay } \\
\text { with PPCL for COPM-S: } \\
\text { 30\% variance explained } \\
\text { for LSS. Only 21\% of } \\
\text { total COPM problem list } \\
\text { is mentioned in PPCL. }\end{array}$ \\
\hline
\end{tabular}

van Meeteren et al., Hemophilia (mild,

2000 [33]
57 D-AIMS2

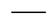

87

Nieuwenhuizen et al., Patients in pain manage2014 (present study) ment program
87

PDI, RAND-36
Spearman: All $-0.3<$ $r<0.3$ (range: -0.26 to 0.248 ), with highest correlations for PDI and RAND-36 vitality and mental health.

RA stage II or III (upper limb, outpatient)

Ripat et al., 2001 [34]
Rochman et al., 2008 Tempomandibular [35]

$$
\text { disorders }
$$

13 HAQ-Disability Index, HAQComponent Score, HAQ-Activity Score

Pearson: COPM-P/total HAQ score $(r=-0.37)$,

COPM-P/matched HAQ-Component Score $(r=-0.52)$, COPM-P/ matched HAQ-Activity Score $(r=-0.67)$.

29 PDI, Global VAS

Pearson (before treatment, after treatment): COPM-P/PDI ( $r=$ $-0.62,-0.75)$, COPM-S/ PDI ( $r=-0.41,-0.79)$, COPM-P/Global VAS $(r=-0.41,-0.42)$, COPM-S/Global VAS $(r=-0.28,-0.39)$.
Percent overlay: $80 \%$ of COPM problems corresponded with content of D-AIMS2. 
Table 1. (cont)

Clinimetric studies evaluating Canadian Occupational Performance Measure (COPM), including present study.

\begin{tabular}{|c|c|c|c|c|c|}
\hline \multirow[b]{2}{*}{ Study } & \multicolumn{3}{|c|}{ Study Characteristics } & \multicolumn{2}{|c|}{ Main Results } \\
\hline & Population & $N$ & $\begin{array}{l}\text { Construct } \\
\text { Measures }\end{array}$ & Correlations & Other Results \\
\hline $\begin{array}{l}\text { Spadaro et al., } 2010 \\
\text { [24] }\end{array}$ & $\begin{array}{l}\text { Ankylosing spondylitis } \\
\text { (mean age: } 48 \text { yr) }\end{array}$ & $\begin{array}{c}30 \\
(24 \mathrm{M} \\
6 \mathrm{~F})\end{array}$ & $\begin{array}{l}\text { BASDAI, BASFI, } \\
\text { BASMI, HAQ }\end{array}$ & $\begin{array}{l}\text { Construct validity. } \\
\text { Spearman: All } r<0.03 \text {, } \\
\text { except: COPM-P/BAS- } \\
\text { DAI }(r=-0.491) \text {, } \\
\text { COPM-S/BASDAI ( } r= \\
\text {-0.566), COPM-P/ } \\
\text { BASFI }(r=-0.566) .\end{array}$ & - \\
\hline $\begin{array}{l}\text { Veehof et al., } 2002 \\
\text { [36] }\end{array}$ & $\begin{array}{l}\text { Variety of unilateral } \\
\text { upper-limb disorders }\end{array}$ & 50 & DASH-DLV & - & $\begin{array}{l}79 \%-83 \% \\
\text { correspondence. }\end{array}$ \\
\hline $\begin{array}{l}\text { Walsh et al., } 2004 \\
\text { [38] }\end{array}$ & LBP outpatient unit & $\begin{array}{c}101 \\
(52 \mathrm{M} \\
49 \mathrm{~F})\end{array}$ & $\begin{array}{l}\text { SEQ, RMDQ, } \\
5 \mathrm{MWT}\end{array}$ & $\begin{array}{l}\text { Spearman: All } r<0.5 \\
\text { (range: }-0.31 \text { to } 0.46 \text { ). At } \\
\text { baseline, COPM-P/SEQ } \\
(r=0.46), 5 \mathrm{MWT} \text { (all } \\
r<0.3) .\end{array}$ & - \\
\hline $\begin{array}{l}\text { Eyssen et al., } 2011 \\
\text { [41] }\end{array}$ & $\begin{array}{l}\text { Various diagnoses (newly } \\
\text { referred to OT) }\end{array}$ & 138 & SIP68, DIP, IPA & $\begin{array}{l}\text { Pearson partial correla- } \\
\text { tions: All } r<0.45 \\
\text { (range: } 0.02-0.42 \text { ). } \\
\text { Highest correlations for } \\
\text { SIP68-Mobility Range } \\
\text { ( } r=0.41) \text {, DIP-Mobility } \\
\text { ( } r=0.39 \text { ), IPA- } \\
\text { Autonomy Indoors ( } r= \\
\text { 0.34), IPA-Family Role } \\
\text { ( } r=0.36), \text { IPA-Autonomy } \\
\text { Outdoors ( } r=0.37) .\end{array}$ & $\begin{array}{l}\text { ROC curves (blind scor- } \\
\text { ing). AUC for COPM-P } \\
\text { (0.79, optimal cut-off } \\
\text { value: } 1.37) \text {, AUC for } \\
\text { COPM-S (0.79, optimal } \\
\text { cut-off value: } 1.90) \text {. ROC } \\
\text { curves (reflective scor- } \\
\text { ing). AUC for COPM-P } \\
\text { (0.79, optimal cut-off } \\
\text { value: } 1.90), \text { AUC for } \\
\text { COPM-S (0.85, optimal } \\
\text { cut-off value: } 1.45) .\end{array}$ \\
\hline
\end{tabular}


JRRD, Volume 51, Number 5, 2014

Table 1. (cont)

Clinimetric studies evaluating Canadian Occupational Performance Measure (COPM), including present study.

\begin{tabular}{|c|c|c|c|c|c|}
\hline \multirow[b]{2}{*}{ Study } & \multicolumn{3}{|c|}{ Study Characteristics } & \multicolumn{2}{|c|}{ Main Results } \\
\hline & Population & $N$ & $\begin{array}{l}\text { Construct } \\
\text { Measures }\end{array}$ & Correlations & Other Results \\
\hline $\begin{array}{l}\text { Kjeken et al., } 2004 \\
\text { [21] }\end{array}$ & Hand osteoarthritis & 79 & $\begin{array}{l}\text { MHAQ, WOMAC, } \\
\text { AUSCAN }\end{array}$ & - & $\begin{array}{l}\text { Responsiveness. COPM } \\
\text { standardized response } \\
\text { mean (>0.7). Mean } \\
\text { change on COPM (sig- } \\
\text { nificantly different from } \\
\text { 0) was larger than } \\
\text { change MHAQ, change } \\
\text { WOMAC, and change } \\
\text { AUSCAN. }\end{array}$ \\
\hline
\end{tabular}

Nieuwenhuizen et al., Patients in pain manage2014 (present study) ment program

Persson et al., 2004 Consecutive pain man[23] agement program clients (different diagnoses)

Spadaro et al., 2010 Ankylosing spondylitis [24] (mean age: 48 yr)

30
$(24 \mathrm{M}$,

$6 \mathrm{~F})$

87 PDI, RAND-36

188

MPI, PGWB

\author{
Spearman: All $r<0.5$ \\ (range: -0.380 to \\ 0.388), with highest cor- \\ relations for PDI, \\ RAND-36-Physical \\ Functioning, and \\ RAND-36-Role Limita- \\ tions (Physical).
}

Pearson: All $r<0.5$

(range: 0.13-0.31), with highest correlations for PGWB-General Health $(r=0.31)$ and MPI-Pain Severity $(r=0.24)$.

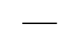

In $n=14$. Change in COPM-P (0.65 \pm 0.55), change in COPM-S $(1.23 \pm 0.69)$. Standardized mean response rates $(>0.7)$.

Spearman: All $r<0.5$ (range: -0.25 to 0.28 ). 5MWT $(r<0.3)$, except for people who stated walking as problem (change between COPM/5MWT: $r=$ 0.35).
Walsh et al., $2004 \quad$ LBP outpatient unit [38] $\begin{array}{cc}101 & \text { SEQ, R } \\ (52 \mathrm{M}, & 5 \mathrm{MWT}\end{array}$

$49 \mathrm{~F})$

108
Wressle et al., 1999 Geriatric, neurologic, [42] 
Table 1. (cont)

Clinimetric studies evaluating Canadian Occupational Performance Measure (COPM), including present study.

\begin{tabular}{|c|c|c|c|c|c|}
\hline \multirow[b]{2}{*}{ Study } & \multicolumn{3}{|c|}{ Study Characteristics } & \multicolumn{2}{|c|}{ Main Results } \\
\hline & Population & $N$ & $\begin{array}{l}\text { Construct } \\
\text { Measures }\end{array}$ & Correlations & Other Results \\
\hline
\end{tabular}

Wressle et al., 2003 RA (day treatment) [25]

\section{Reproducibility}

Cup et al., 2003 [17] Stroke

26

$-$

Eyssen et al., 2005

[43]

Various diagnoses (newly referred to OT)

95

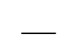

Kjeken et al., 2005 Ankylosing spondylitis [44]

Pan et al., 2003 [45] Psychiatric disorders

Sewell \& Singh, 2001 Chronic pulmonary [46]

disease

15
1193 modes: personal interview, telephone, mail

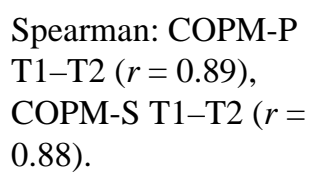

Spearman: COPM-P T1-T2 ( $r=0.89)$, COPM-S T1-T2 $(r=$ 0.88).

ICC performance: 0.65 (range: 0.54-0.78), ICC satisfaction: 0.69 (range: 0.56-0.79).

ICC COPM personal interview were best: COPM-P: 0.92 (range: 0.78-0.97), COPM-S: 0.93 (range: $0.83-0.98$ ).
Wilcoxon test baseline (posttreatment) different from 0. COPM-P ( $p=$ 0.004), COPM-S ( $p=$ 0.000).

Mean satisfaction. T1 (3.3 \pm 1.9$),$ T2 (3.5 \pm 2.1). Mean performance. T1 (3.5 \pm 1.8$)$, $\mathrm{T} 2$ (3.7 \pm 1.9$)$. 3/5 problems identified at both occasions.

$66 \%$ of prioritized problems at T1 were prioritized at $\mathrm{T} 2$.

Smallest detectable difference in COPM personal interview (SD: 1.96 of difference between baseline and retest), COPM-P (1.47), COPM-S (1.80). Other modes showed less sensitive results.

ICC: COPM-P (0.842), COPM-S (0.847).

- Spearman: COPM-P
T1-T2 $(r=0.81)$
COPM-S T1-T2 $(r=$
0.76).
0.76).

30 $6 \mathrm{~F}$ )
ICC (1 wk): COPM-P ( $r=0.77$, 95\% CI: 0.520.89), COPM-S ( $r=$ 0.79, 95\% CI: 0.560.90). Outliers! 
JRRD, Volume 51, Number 5, 2014

Table 1. (cont)

Clinimetric studies evaluating Canadian Occupational Performance Measure (COPM), including present study.

\begin{tabular}{|c|c|c|c|c|c|}
\hline \multirow[b]{2}{*}{ Study } & \multicolumn{3}{|c|}{ Study Characteristics } & \multicolumn{2}{|c|}{ Main Results } \\
\hline & Population & $N$ & $\begin{array}{l}\text { Construct } \\
\text { Measures }\end{array}$ & Correlations & Other Results \\
\hline $\begin{array}{l}\text { Verkerk et al., } 2006 \\
\text { [37] }\end{array}$ & $\begin{array}{l}\text { Parents of disabled } \\
\text { children }\end{array}$ & 80 & - & - & $\begin{array}{l}80 \% \text { of problems re- } \\
\text { identified in retest. Lim- } \\
\text { its of agreement of scor- } \\
\text { ing: COPM-P }(-2.4 \text { to } \\
2.3, \Delta: 0.7 \pm 1.2) \text {, } \\
\text { COPM-S }(-2.3 \text { to } 2.6 \text {, } \\
\Delta: 0.18 \pm 1.2) \text {. }\end{array}$ \\
\hline
\end{tabular}

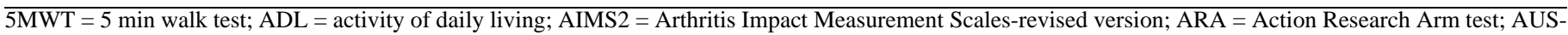

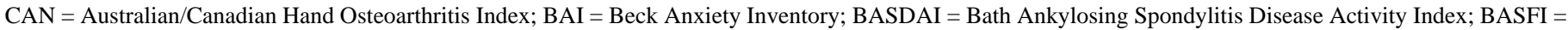

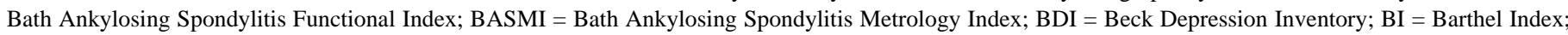

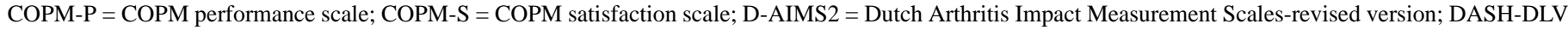

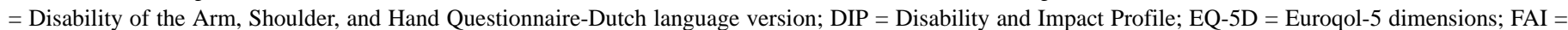

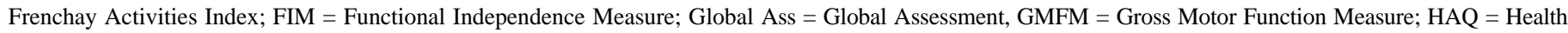

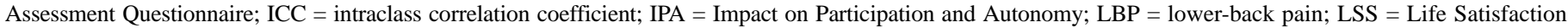

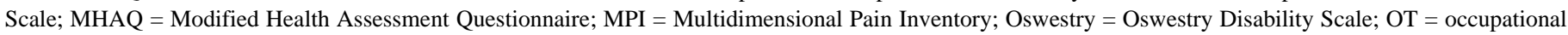

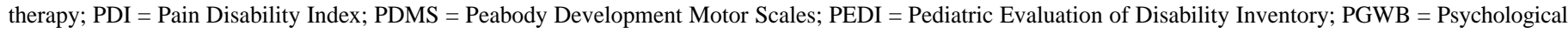

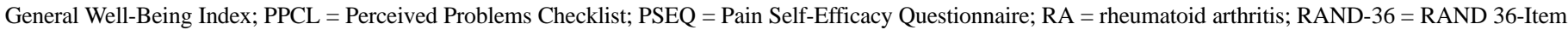

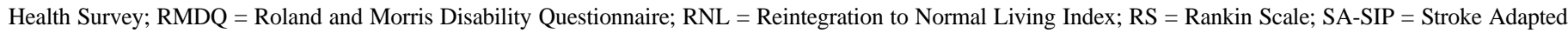

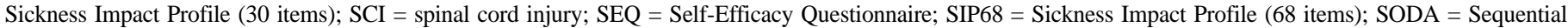

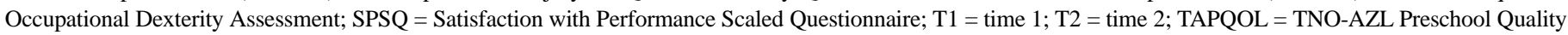

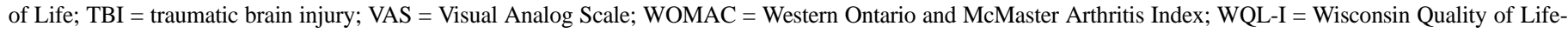
Client Questionnaire.

constructed to measure physical, emotional, or mental functioning, impairment, or quality of life.

Clinically, the most important score of the COPM is the change score measuring change between the scores at an initial evaluation (at admission) and the scores at reevaluation (for instance, at discharge) [17,42]. Although this implies that evaluation of the responsiveness to change over time is an important and necessary aspect of the validating process, it has often been left unstudied. The most recent investigation of the responsiveness of the COPM was conducted by Eyssen et al. [41]. They studied the responsiveness in consecutive clients of an outpatient occupational therapy department by comparing the change scores on the COPM with the change in Sickness Impact Profile (SIP), the Disability and Impact Profile (DIP), and the Impact on Participation and Autonomy (IPA) scores. The COPM was moderately and positively correlated with most SIP, DIP, and IPA subscores and considered sufficiently responsive. However, Eyssen et al.'s population was not fully comparable with the population in a pain rehabilitation program regarding issues of emotional and psychological functioning and these results cannot be adopted without further research [41].
Four studies investigated the clinimetric properties of the COPM in patients with chronic pain $[23,29,35,38]$. Of these studies, Rochman et al. [35] and Carpenter et al. [29] studied the validity of the COPM and showed low correlations at baseline and moderate correlations after treatment for performance (COPM) and pain severity, pain-related disability, self-efficacy related to pain, psychological well-being, and psychosocial functioning. The only studies that investigated responsiveness of the COPM in patients with chronic pain were performed by Walsh et al. [38] and Persson et al. [23]. Walsh et al. reported no correlations between COPM performance scale (COPM-P) and COPM satisfaction scale (COPMS) change scores and the Roland Morris Disability Questionnaire and low correlations with changes on a selfefficacy questionnaire [38]. Furthermore, Walsh et al. found a small association between the change on a $5 \mathrm{~min}$ walk test and COPM walking-associated performance score [38]. In their Swedish cohort of 188 participants of a pain management program, Persson et al. found that a positive change on the COPM (performance and satisfaction scales) was associated with positive changes in psychological well-being and the Multidimensional Pain Inventory domains of general activity level, general 
health, and vitality [23]. Both studies concluded that the COPM is responsive to change on account of significant correlations, although these correlations were low.

After scrutinizing the literature (Table 1), we found that the COPM has not yet been validated in a Dutch pain population. In addition, although many different measures have been used as anchors, the Pain Disability Index (PDI), a pain-specific instrument, has only been used once, and the RAND-36, a very common quality of life questionnaire, has never been taken into account.

Therefore, the aim of this study was to examine the construct validity and construct responsiveness of the Dutch version of the COPM-P [49] in a population with chronic pain by comparing the results with results on a diagnosis-specific measure of functioning, the PDI [50], and a generic quality of life scale, the RAND-36 [51]. We hypothesized that the COPM-P score is linked positively to quality of life and negatively to pain-related disability. While the constructs quality of life and functioning/disability are clearly different from patient-specific problems, we assumed we would find moderate associations between the COPM-P and the RAND-36 or the PDI measured at one moment in time. Since the goal of a pain rehabilitation program is both to help patients master their performance problems and to increase quality of life, we expected to measure improvements on all instruments. Therefore, regarding the change over time (responsiveness), we expected the results on the COPM$\mathrm{P}$ to correlate more strongly with those on the PDI and the RAND-36.

\section{METHODS}

\section{Patients}

The study population consisted of 87 outpatients participating in the chronic pain rehabilitation program of the Reade Center for Rehabilitation and Rheumatology in Amsterdam, the Netherlands. Inclusion criteria for the rehabilitation program were dysfunctioning in daily life activities and role fulfillment due to chronic pain of the musculoskeletal system existing for more than $6 \mathrm{wk}$ (usually $>1$ yr), complex social and psychological factors considered as important or the most important maintaining factors, age at or above $18 \mathrm{yr}$, ability to communicate in Dutch well enough to discuss feelings and thoughts, no active psychiatric disorders diagnosed and no apparent substance abuse (alcohol and drugs except analgesics), no known malignant illness, and no pregnancy. Patients gave informed consent about the focus of the rehabilitation program, in that dealing with pain instead of pain relief was the main focus. To gather demographic characteristics of the patients included in this study, we administered a short questionnaire.

\section{Design}

We assessed the construct validity and construct responsiveness of the COPM-P by comparing the COPM-P score with the scores of the PDI and the RAND-36. The aim of these instruments is to measure the effect of chronic pain on functioning or quality of life. All patients who gave their written informed consent were enrolled in the study. The participants filled out and returned the self-administered questionnaires that had been sent to them just before they took part in the pain rehabilitation program. In the last week of the program, participants were given the same questionnaires to fill out once again. The COPM interview was applied in the first and last week of the chronic pain rehabilitation program.

\section{Chronic Pain Rehabilitation Program}

The outpatient pain rehabilitation program of the Reade Center for Rehabilitation and Rheumatology in Amsterdam, developed in 2005, was based on interdisciplinary cognitive behavioral therapy. The team consisted of a rehabilitation physician, psychologists, a social worker, physiotherapists, occupational therapists, and a psychomotor therapist. The program aimed to increase patients' awareness about ineffective pain responses as well as give training in alternative behavioral patterns during occupational and sports activities and social interaction-based training. The whole program was grouporiented, and rehabilitation groups were comprised of four to eight people. During the group sessions, the therapists worked together in an interdisciplinary manner. The program combined, among other things, rational emotive behavioral therapy with psychoeducation sessions (given by a psychologist and social worker), graded activity and graded exposure groups (physical therapists, occupational therapists, and psychologists working together), basic body awareness sessions (physical therapists and occupational therapists), and pacing and planning sessions (occupational therapists and physical therapists). Patients were invited to practice new behavior during six sessions in the swimming pool, six sessions in the sports hall (physical therapists and occupational therapists), and one cooking session (occupational therapists and one of 
the other therapists). Besides the group therapy, the program consisted of individual coaching sessions for each patient to specify and work toward individual goals. All occupational therapists, physical therapists, and the social worker were trained to coach patients, and individual goals were communicated to the whole team in team meetings. The COPM was used to discuss areas of activity that may present problems and to rate these problems in order to facilitate goal setting. During the first week of the program, the participants were invited for an interview with one of the therapists to assess the personal goals for the program. In a specific module, significant others were invited as well to discuss their role in managing life with pain. Patients were in the rehabilitation center for $12 \mathrm{wk}, 3 \mathrm{~d} / \mathrm{wk}$, for approximately $4 \mathrm{~h} / \mathrm{d}$. If necessary, patients saw a psychologist individually as well.

\section{Instruments}

\section{Canadian Occupational Performance Measure}

The official Dutch translation of the COPM was used [49]. The COPM, built on the Canadian Model of Occupational Performance and the framework of client-centered practice [16,52], is an individualized measure designed for use by occupational therapists to, among other aims, detect a self-perceived change in occupational performance problems over time. The COPM was designed for use as an outcome measure and to assist the client and the therapist to identify problems in the three areas of occupational performance: self-care, productivity, and leisure. In a semistructured interview, the client identifies and prioritizes occupational performance problems. Up to five problems are selected as the most important at the time. The client subsequently rates the performance and satisfaction with performance in each problem area using Likert scales, where $1=$ not able to do/not satisfied at all and $10=$ able to do extremely well/extremely satisfied. The COPM thus yields two subscale scores: performance (COPM-P) and satisfaction (COPM-S). In the present study, only the COPM-P scores were analyzed, because (1) the satisfaction with performance is assumed to be a different construct and should be validated against different anchors, and (2) the satisfaction with performance was often difficult for patients to score and, therefore, mirrored the score of performance. To calculate the score, the problem ratings were summed and divided by the number of problems prioritized, giving the mean score. The mean COPM-P score ranges from 1 to 10 .
The COPM was repeated after the chronic pain rehabilitation program and change scores were obtained by subtracting the prior score from the last [20]. Patients were blinded or at least naïve to their admission scores. Change of two or more points on the COPM-P is considered clinically significant by the developers of the instrument [20]. It is advocated that the instrument is administered by a trained occupational therapist. However, in the chronic pain rehabilitation team at Reade, the physiotherapists and the social worker as well as the occupational therapists were responsible for administering the COPM.

All involved healthcare professionals have their professional competencies to interview patients. In addition, the team members received extra training to improve and to enlarge their interviewing skills (e.g., by motivational interviewing techniques). Client-centered interviewing and the administration of the COPM were explained by the occupational therapists and practiced. Furthermore, as part of the usual team work, several team meetings were used to discuss difficulties that occurred during the COPM interviews when priorities were set. These meetings did not influence the rating of the COPM priorities either at admission or at the end of the program.

\section{Pain Disability Index}

The PDI is a brief self-administered questionnaire consisting of seven questions that measure the extent to which pain interferes with daily activity areas [50]. The seven areas of role functioning that are taken into account are home and family responsibilities, recreation, social activities, occupation, sexual functioning, self-care, and life support activities. Patients indicate the amount of perceived pain-related disability for each category on 11point Likert scales, with higher scores indicating greater disability. The overall score is the summation of the seven ratings. The PDI has shown to have good clinimetric properties in various samples of patients with chronic pain [53-55]. In the data of the present study, we observed that, at admission, the item on sexual functioning of the PDI was missing in 8 percent of the returned questionnaires. Some of the patients reported in writing that this specific question was not applicable for their situation. On that account, we judged that the missing values on the item were not at random and decided to exclude the item from the total score. Besides that, sex-related problems were not mentioned in the COPM-P priorities. Thus, in the analyses, the PDI score is the summation of six items, ranging from 0 to 60 . 


\section{RAND 36-Item Health Survey}

The RAND-36 is an HR-QOL measure that obtains patients' own assessment of their functioning, wellbeing, and perceived general health during the past $4 \mathrm{wk}$ [51]. The RAND-36 consists of eight domains: physical functioning, social functioning, role limitations due to physical problems, role limitations due to emotional problems, mental health, pain, vitality, general health, and one item dealing with perceived health changes. Questions can be answered by response choices ranging from two to six. Of every domain, a summation score can be calculated, with higher scores reflecting a better functioning or quality of life. The RAND-36 has been found to have sufficient clinimetric properties [45,56-58]. In the analyses of the current study, all domains were included. The single item on perceived health changes was left out of the analyses. In this study, the way of dealing with missing items proposed by Van der Zee and Sanderman [58] was followed: when at least half of the items for a domain had been scored, the missing items were imputed by the mean score of the scored items. When less than half of the items were scored, the domain score was not calculated. All RAND-36 domain scores range from 0 to 100 , with higher scores indicating better quality of life.

\section{Statistical Analysis}

Before testing for associations, the distribution of the data was checked. Floor and ceiling effects were considered to be present if more than 15 percent of the respondents achieved the lowest or highest possible score, respectively [59]. Skewness was considered to be present if the corresponding statistic was less than -1.0 or more than 1.0. Demographics of the study group and characteristics of the questionnaires were described by frequencies and mean scores.

Differences in personal characteristics (sex, age, cultural background) and baseline scores on the COPM-P, PDI, and RAND-36 scores between participants and dropouts were tested with a chi-square test or independent $t$-test.

\section{Construct Validity}

The construct validity of the COPM was determined by comparing the COPM-P score with the PDI and the eight domains of the RAND-36 at baseline. We expected to find convergent though weak to moderate correlations ( $r=0.20-0.50$ ) between the COPM and the PDI and the RAND-36 because these instruments actually measure different concepts.

\section{Construct Responsiveness}

In accordance with Terwee et al. [59] and Mokkink et al. [60-61], we considered responsiveness to be a measure of longitudinal validity that should be assessed by testing predefined hypotheses. Responsiveness was measured by evaluating the correlations among changes on the COPM-P, PDI, and RAND-36 from start of treatment to the end of the therapy period of $12 \mathrm{wk}$. We expected stronger correlations between the change scores than between the scores at one measurement. A correlation of $>0.50$ was expected between the change scores of the COPM-P and the PDI [35]. For the RAND-36, no references were found in the literature, and we presumed that the correlations would be acceptable when $r>0.40$ because quality of life is based on multiple factors.

Nonparametric Spearman correlations were used in all analyses. Generally, correlations are considered low $(<0.20)$, moderate $(0.20-0.50)$, or high $(>0.50)$ according to the recommendations of Cohen [62].

In case at least 75 percent of the correlation coefficients met our criteria [63], the construct validity or construct responsiveness of the COPM-P was confirmed.

The data were analyzed using SPSS version 15 (IBM Corporation; Armonk, New York).

\section{RESULTS}

\section{Descriptives}

Of the 114 patients invited to participate, 20 were unwilling to participate and another 7 patients were excluded because COPM-P scores were not obtained during the first interview due to lack of time or because the patient was not able to identify problems with activities. The 27 nonincluded patients did not differ from the included group with respect to age, sex, and pain localization. The study population was comprised of 87 patients, mostly women (82\%), with a mean age of $42 \mathrm{yr}$ (range: 20-66 yr) and mainly of Western European background $(78.1 \%)$. Pain diagnoses included whiplashassociated disorders (36\%) and low back pain (21\%) followed by widespread pain; complaints of arm, neck, and/or shoulder; fibromyalgia; and other diagnoses (Table 2). All but three patients had lived with these complaints for $>1$ yr. Table 2 shows other patient characteristics.

The mean COPM-P score was $3.43 \pm 1.21$ (mean \pm standard deviation) out of 10 (Table 3). The distribution of this score was sufficiently symmetric, skewness was within limits, and no floor or ceiling effects were observed. 
JRRD, Volume 51, Number 5, 2014

Table 2.

Characteristics of patients with chronic pain at start of treatment $(N=87)$.

\begin{tabular}{|c|c|}
\hline Characteristics & Mean \pm SD or $n(\%)$ \\
\hline \multicolumn{2}{|l|}{ Personal } \\
\hline Age (yr) & $41.7 \pm 11.4$ \\
\hline Non-Western Cultural Background & $19(21.8)$ \\
\hline \multicolumn{2}{|l|}{ Marital Status } \\
\hline Single, Divorced, or Widowed & $38(43.7)$ \\
\hline Living Apart Together* & $7(8.1)$ \\
\hline Having Children Living at Home & 29 (33.3) \\
\hline \multicolumn{2}{|l|}{ Level of Education } \\
\hline Low & $16(18.4)$ \\
\hline Medium & $36(41.4)$ \\
\hline Working & $28(32.2)$ \\
\hline On Sick Leave (partial or full) & $38(43.7)$ \\
\hline Unemployed & $38(43.7)$ \\
\hline Receiving Disability Pension or Sick Pay & 69 (79.3) \\
\hline Legal Suit & $31(35.6)$ \\
\hline \multicolumn{2}{|l|}{ Pain } \\
\hline \multicolumn{2}{|l|}{ Localization } \\
\hline Nonspecific Chronic Low Back Pain & $18(20.7)$ \\
\hline Whiplash-Associated Disorder (complaints in neck/head region) & $31(35.6)$ \\
\hline Complaints of Arm, Neck, and/or Shoulder & $12(13.80)$ \\
\hline$<5$ & $40(46.0)$ \\
\hline
\end{tabular}

${ }^{*}$ People in a sustainable relationship not sharing household by choice.

$\mathrm{SD}=$ standard deviation.

The mean PDI score in our population was $34.9 \pm 7.72$, indicating mild to moderate disability due to pain. According to the RAND-36, the subjects on average felt very constrained in their role fulfillment and experienced pain and a loss of energy and/or vitality at the start of the treatment program (Table 3 ). There were very wide ranges in the scoring on all domains. All scores except those for RAND-36 role fulfillment due to physical problems and role fulfillment due to emotional problems complied with our requirements on floor and ceiling effects.

\section{Canadian Occupational Performance Measure Priorities}

The COPM was aimed to measure meaningful occupational performance, written down as activities of daily living capturing self-care, productivity, leisure activities, and religion. To give an idea about the sort of entries our patients gave on the COPM priorities, we classified the problems by the two lists of the internationally accepted and widely used International Classification of Functioning, Disability, and Health (ICF): "body functions and 
Table 3.

Outcome measures.

\begin{tabular}{|c|c|c|c|c|c|c|}
\hline \multirow{2}{*}{ Outcome Measure } & \multicolumn{2}{|c|}{ Score at Admission } & \multicolumn{2}{|c|}{ Score at End of Treatment } & \multicolumn{2}{|c|}{ Change Score } \\
\hline & $n$ & $\overline{\text { Mean } \pm \text { SD }}$ & $n$ & Mean \pm SD & $n$ & Mean \pm SD \\
\hline COPM-P & 87 & $3.43 \pm 1.21$ & 69 & $5.75 \pm 1.69$ & 69 & $2.27 \pm 1.28^{*}$ \\
\hline PDI & 84 & $34.30 \pm 7.59$ & 69 & $30.00 \pm 8.64$ & 67 & $-4.04 \pm 6.69^{*}$ \\
\hline \multicolumn{7}{|l|}{ RAND-36 } \\
\hline Physical Functioning & 82 & $48.90 \pm 19.8$ & 71 & $51.90 \pm 21.39$ & 72 & $3.04 \pm 14.67$ \\
\hline Social Functioning & 87 & $42.30 \pm 22.4$ & 72 & $49.49 \pm 23.02$ & 72 & $8.50 \pm 23.53^{*}$ \\
\hline Mental Health & 85 & $58.70 \pm 17.0$ & 70 & $62.23 \pm 18.82$ & 72 & $4.94 \pm 16.84^{*}$ \\
\hline Vitality & 87 & $37.10 \pm 17.4$ & 72 & $45.49 \pm 18.48$ & 72 & $10.14 \pm 17.03^{*}$ \\
\hline Pain & 87 & $37.30 \pm 16.1$ & 71 & $42.63 \pm 18.80$ & 72 & $4.51 \pm 18.17$ \\
\hline General Health Perception & 85 & $44.70 \pm 17.6$ & 71 & $49.72 \pm 18.48$ & 69 & $4.64 \pm 15.61^{*}$ \\
\hline
\end{tabular}

structures" and "activity and participation.” The 87 included patients prioritized 380 problems they encountered in daily life. Although we expected all entries of the COPM to be on the activities and participation level of the ICF [64], a little over 30 percent of the prioritized problems could be classified as problems at the level of body and mental functions of the ICF, of which the majority were classified in the chapters "global mental functions" and "specific mental functions," subsections "energy and drive functions," "attention functions," "sleep function," "muscle tone functions," and "exercise tolerance” (Table 4). Of the 230 problems at the activity and participation level, 55 (24\%) could be categorized in the ICF section "mobility" (Table 4).

Table 4.

Canadian Occupational Performance Measure priorities of 87 patients with chronic pain categorized by International Classification of Functioning, Disability, and Health (ICF) chapter.

\begin{tabular}{|c|c|}
\hline ICF Chapter & Total \\
\hline Body Functions & 122 \\
\hline $\begin{array}{l}\text { Neuromusculoskeletal and Movement-Related Functions (e.g., muscle strength, muscle endurance, } \\
\text { control of voluntary movement, sensations related to muscles and movement) }\end{array}$ & 13 \\
\hline Activities and Participation & 230 \\
\hline Mobility (e.g., changing and maintaining body positions, walking, using transportation) & 55 \\
\hline Community, Social, and Civic Life (e.g., recreation and leisure, community life) & 48 \\
\hline Interpersonal Interactions and Relationships & 37 \\
\hline Major Life Areas (e.g., education, work and employment, economic life) & 34 \\
\hline Self-Care & 4 \\
\hline Communication & 2 \\
\hline Not Classified & 28 \\
\hline Total & 380 \\
\hline
\end{tabular}




\section{Construct Validity}

The direction of the nine correlation coefficients was as expected: positive for the eight RAND-36 domains and negative for the PDI. A weak correlation between the COPM-P and the PDI was found ( $r=-0.260$, Table 5). The highest correlations between the COPM-P and RAND-36 were found for the domains of vitality ( $r=$ $0.248)$ and mental health $(r=0.206)$. For all other domains, no relationships with the COPM-P were found. Three out of nine correlations (33\%) met the stated criteria; these results did not confirm the a priori stated expectations.

\section{Construct Responsiveness}

At the end of the program, it was not possible to retrieve complete data for 30 patients: 12 refused to fill out the questionnaires (PDI and RAND-36) again, and in 18 cases, the COPM-P was not scored during the last interview. In the group that dropped out, relatively more patients with a whiplash-associated disorder were present. These patients were not different from the others in terms of sex $(p=0.86)$; age ( $p=0.58)$; cultural background ( $p=0.31)$; or baseline scores on the COPM-P ( $p=$ 0.79 ), PDI $(p=0.58$ ), and RAND-36 (ranging from $p=$ 0.06 [pain] to 0.65 [mental health]). Therefore, the responsiveness results are based on 57 participants.

COPM-P scores improved significantly $(p<0.001)$ during the rehabilitation program as well as the PDI score $(p<0.001)$ and the RAND-36 scores for social functioning $(p<0.005)$, mental health $(p<0.005)$, vitality $(p<$

Table 5.

Construct validity: Spearman correlations between Canadian Occupational Performance Measure performance scale (COPM-P) and Pain Disability Index (PDI) and RAND 36-Item Health Survey (RAND-36) domains at start of treatment.

\begin{tabular}{lc}
\hline \multicolumn{1}{c}{ Outcome Measure } & COPM-P Score \\
\hline PDI & -0.260 \\
RAND-36 & \\
Physical Functioning & 0.106 \\
Social Functioning & 0.125 \\
Role Limitations (Physical) & -0.007 \\
Role Limitations (Emotional) & 0.161 \\
Mental Health & 0.206 \\
Vitality & 0.248 \\
Pain & 0.184 \\
General Health Perception & 0.106 \\
\hline \hline
\end{tabular}

0.001), and general health $(p<0.05)$ (Table 3). The group responded very heterogeneously to the pain rehabilitation program as measured with the COPM-P, with patients who showed large improvements, while others (3 patients) showed a deterioration (total range of COPM-P change scores: -1.00 to 5.40 ). A clinically significant improvement of two or more points on the COPM-P was scored by 44 (63.8\%) patients. Within-patient comparison of the change scores on these instruments showed, however, the largest correlations between COPM-P and PDI $(r=-0.380)$, RAND-36 physical functioning ( $r=$ 0.388), RAND-36 role limitations (physical) $(r=0.302)$, and RAND-36 social functioning $(r=0.388)$. In general, the correlations between the COPM-P change score and the change on the PDI $(r=-0.380)$ and the RAND-36 ( $r=$ 0.273-0.388) (Table 6) were not as strong as expected a priori. However, all results were in the expected direction (patients improved on all scales), and correlations between change scores seemed to be stronger than those of scores at admission.

\section{DISCUSSION}

This study focused on the construct validity and construct responsiveness of the COPM-P in a population of patients with chronic pain using the RAND-36 and PDI as anchor questionnaires. The results of this study showed that the COPM-P was only weakly to moderately associated with the outcomes of the PDI and RAND-36.

Table 6.

Construct responsiveness: Spearman correlations between change scores on Canadian Occupational Performance Measure performance scale (COPM-P) and on Pain Disability Index (PDI) and RAND 36Item Health Survey (RAND-36) subdomains.

\begin{tabular}{lcc}
\hline Outcome Measure & $\Delta$ COPM Score \\
\hline$\triangle$ PDI & -0.380
\end{tabular}

$\triangle$ RAND-36

Physical Functioning $\quad 0.388$

Social Functioning $\quad 0.302$

Role Limitations (Physical) 0.381

Role Limitations (Emotional) $\quad 0.139$

Mental Health $\quad 0.084$

Vitality $\quad-0.031$

Pain $\quad 0.160$

General Health Perception $\quad 0.273$ 
We were not able to find support for the construct validity and responsiveness of the COPM-P in this population and setting. Although many authors have explained their results differently, the results of this study are in line with prior studies, finding mostly low or no correlations $[17,21,29-31,34,38]$.

In our treatment program, the COPM is administered by occupational therapists as well as other experienced team members. All therapists were trained by occupational therapists in administering the COPM. Critical readers might argue that the COPM was designed to be used only by occupational therapists and that our practice would subvert the validation of the measure. Because the COPM is measuring the self-perception of occupational performance by patients over time, we assumed that the specific diagnostic skills or knowledge of occupational therapy were less essential than good interviewing skills, and therefore, all team members should be able to work with the measure. Working in a rehabilitation center demands that the therapists formulate treatment goals on the level of activities and participation. The setting of this study was the common practice in a pain rehabilitation program. It would have been interesting to compare means scores and problem category distribution among interviewers. However, the numbers of patients per interviewer were really too small to allow valid comparisons among interviewers. This could be a subject for future studies.

The COPM was designed to measure occupational performance of activities of daily living important to the patient. We categorized the answers in the ICF chapters of activities and participation or functions, expecting that no or only few of the answers were in the functions chapter. However, approximately one-third of the problems prioritized by the patients in the present study concerned body and mental functions. It requires good communication skills and adequate clinical reasoning of the interviewer to redirect patients from thinking in functions toward mentioning problematic activities. Either the interviewers were not alert enough to redirect patients toward activity outcomes or it was too difficult for patients to think about what specific activities they were not able to do or could not do as well as they wanted to or was expected from them. Frequently, patients mentioned that all their activities were affected by their pain and lack of energy, and they were not able to identify specific activities. Others mentioned they were able to perform every specific activity but were not able to do as many activities as they wanted during the day. In these cases, the underlying disabilities were taken into account. One could argue that a client-centered measure should give the opportunity to mention problems in body and mental functions, especially when it gives directions for treatment in daily practice. On the other hand, the construct of the measure might be jeopardized by this practice.

Unfortunately, we were not able to include a sufficient number of patients to do subgroup analyses based on type of priorities. This would have been an interesting exercise, because a possible correlation between COPM$\mathrm{P}$ and PDI or RAND-36 domains in patients who prioritized problems at activity and participation level might be obscured by the results of patients who primarily reported problems at function level. In the future, it would make sense to first determine the most commonly given priorities in a certain population prior to the selection of the comparison instrument in construct validity or responsiveness testing of the COPM.

We have taken the single average COPM-P score into account for this study, according to how the COPM-P score should be obtained by the manual. In this way, all problems are equally weighted, although patients might view the problems listed first as more important or more relevant in their self-rating of disability or quality of life. It might be a short-coming of the COPM that there is no weighting strategy for the priorities given, although this is not under investigation. Weighting problems or selecting only the problems of highest priority might be subject to future research.

A reason why strong associations between existing scales and the COPM were not expected was explained in a critical appraisal by Jolles et al. [48]. They concluded that although the value of patient-specific indices such as the COPM in treatment planning and monitoring at an individual level is strong, the heterogeneous item content across patients and the differences in scaling among individuals makes it less appropriate to use these measures in groups. Also de Vet et al. stated that, to provide evidence of construct validity, one needs to clarify and describe the construct measured by the instrument and one needs to formulate hypotheses with regard to expected relationships with other instruments, measuring the same or related constructs [65]. Regarding the nature of the COPM, a common specified and described construct is not available, rendering the necessary validating process of the COPM difficult, and we have to interpret validation reports with care. 
Chen et al. found higher associations between the COPM and the Reintegration to Normal Living Index (RNL) [39]. The theoretical background of the RNL resembles the theoretical background of the COPM. For that reason, it could have correlated better with the COPM in the study of Chen et al. [39]. However, this cannot be said with certainty. The RAND-36 and PDI were, in our opinion, the best measures available to us. If the RNL is translated and validated in Dutch, future studies might reveal whether the low associations that were found in this study were due to either the validity of the COPM or a less favorable comparison with the RAND36 and PDI.

The 12 wk chronic pain rehabilitation program at Reade is aimed at increasing people's ability to cope with their incurable pain, thereby restoring daily functioning and improving quality of life. In that respect, one would expect improvements on outcome measures for global quality of life (i.e., RAND-36), pain-related disability (i.e., PDI), and especially on an outcome measuring people's occupational performance (i.e., COPM). The COPM-P score improved significantly, as did the scores on some domains of quality of life (social functioning, mental health, vitality, and general health). The extent to which pain interfered with daily life significantly reduced as well. Both Persson et al. [23] and Carpenter et al. [29] revealed a significant improvement of COPM-P after a pain rehabilitation program as well, resembling the program of Reade, supporting the absolute responsiveness of the COPM.

The weak to moderate correlations found in the present study regarding construct responsiveness, however, were comparable with two previous studies in chronic pain populations $[23,38]$ and to one study with a mixed population [41]. The study that revealed high correlations $(r=0.72)$ was done in a small and different patient group, and the COPM was compared with other instruments, which makes it hard to compare our results with Chen et al. [39] and Pan et al. [45]. Finding low or no correlations between the change scores of the COPM-P and RAND36 or PDI could suggest that either the COPM-P is measuring a different construct and unrelated to the other measures (although it was assumed otherwise), the fixed items of the comparing questionnaires are less sensitive for change, or other phenomena play a role in obscuring effects (correlations). It is difficult to conclude which of these three explanations might be right, based on the results of the present study.
Without exception, all prior studies [17,21,29-31,38] that also found low correlations (Table 1) have explained these results by stating that the COPM and other measures do actually approach different constructs or by the fact that other instruments are using fixed items and are not sensitive enough to reveal the real issues of a patient and his or her actual recovery. However, one would expect that large improvements on specific problematic activities indicated as most important to the patient would have implications on the overall quality of life of a patient, and therefore, higher correlations could be found in the subgroup of patients with high COPM change scores and their quality of life. Therefore, we performed a subgroup analysis in patients who showed a clinically significant improvement of $\geq 2$ points on the COPM-P. Similar correlations were found (results not presented).

The COPM interview is not suitable or feasible for every patient with chronic pain because they are not able to either state performance problems or to score them. Since "decision making skills," "setting limits," "prioritizing," and "focusing" are defined as important problems in a considerable number of patients with chronic pain [66-67], it is not a surprising finding that in some patients, it turned out to be impossible to obtain COPM priorities and scores at all or that stated priorities became irrelevant during the course of the program.

Our change scores might be limited due to the selective dropout of patients; however, there were no differences in patient characteristics at admission.

In the present study, the COPM was not administered by an independent investigator. Instead, it was executed by the coach-therapist of the patient in the treatment program, reflecting common institutional practice. One phenomenon that could play a part when administering the COPM by a therapist is the "hello-goodbye effect," where patients underestimate their abilities at the first visit and overestimate their abilities at the end of treatment [68]. This often occurs when patients are interviewed by their own therapists. At first, their eagerness to get help will force them to underestimate their abilities, and after treatment, their relationship with the therapist might cause them to exaggerate their scores. By comparing the COPM with other subjective and self-administered questionnaires like the PDI and RAND-36, we were not able to pinpoint a low correlation to the effect of this socalled hello-goodbye effect. A future study, comparing the results of individuals who fill out the form with an independent interviewer with those of people who are 
interviewed by a therapist in a therapy setting, might clarify whether this phenomenon does indeed obscure real or true results of the COPM. In the past, face-to-face interviewing and self-administering COPM were compared for reliability of results [44]. The face-to-face interviews were most reliable.

\section{CONCLUSIONS}

In conclusion, in patients with chronic pain, the COPM-P measures a different construct than the PDI or RAND-36. Although many of our patients showed an absolute improvement in COPM-P scores, an indication of relative construct responsiveness of the COPM-P, as compared with the PDI and RAND-36, could not be found, taking into account the levels of acceptance stated in this study. Based on our results and the outcomes of previous studies, the COPM should be interpreted with care when used as an evaluative measurement instrument. However, the measure can be helpful in structuring a patient's thoughts on the problems he or she is facing and setting specific goals for therapy.

\section{ACKNOWLEDGMENTS}

\section{Author Contributions:}

Study concept and design: M. G. Nieuwenhuizen, S. de Groot, H. Beckerman.

Acquisition of data: L. C. C. van der Maas.

Analysis and interpretation of data: M. G. Nieuwenhuizen,

S. de Groot.

Drafting of manuscript: M. Nieuwenhuizen.

Critical revision of manuscript for important intellectual content:

S. de Groot, T. W. J. Janssen, L. C. C. van der Maas, H. Beckerman.

Financial Disclosures: The authors have declared that no competing interests exist.

Funding/Support: This material was based on work supported by the Duyvensz-Nagel Stichting, Amsterdam, the Netherlands.

Institutional Review: All tests and protocols were approved by the medical ethics committee of the VU University Medical Center, and all participants provided informed consent.

Participant Follow-Up: The authors plan to inform participants of the publication of this study.

\section{REFERENCES}

1. Breivik H, Collett B, Ventafridda V, Cohen R, Gallacher D. Survey of chronic pain in Europe: prevalence, impact on daily life, and treatment. Eur J Pain. 2006;10(4):287-333. [PMID:16095934]

http://dx.doi.org/10.1016/j.ejpain.2005.06.009

2. Stanos S, Houle TT. Multidisciplinary and interdisciplinary management of chronic pain. Phys Med Rehabil Clin N Am. 2006;17(2):435-50, vii. [PMID:16616276] http://dx.doi.org/10.1016/j.pmr.2005.12.004

3. Dysvik E, Kvaløy JT, Stokkeland R, Natvig GK. The effectiveness of a multidisciplinary pain management programme managing chronic pain on pain perceptions, health-related quality of life and stages of change-A nonrandomized controlled study. Int J Nurs Stud. 2010;47(7): 826-35. [PMID:20036362] http://dx.doi.org/10.1016/j.ijnurstu.2009.12.001

4. Guzmán J, Esmail R, Karjalainen K, Malmivaara A, Irvin E, Bombardier C. Multidisciplinary bio-psycho-social rehabilitation for chronic low back pain. Cochrane Database Syst Rev. 2002;(1):CD000963. [PMID:11869581]

5. Williams AC, Nicholas MK, Richardson PH, Pither CE, Justins DM, Chamberlain JH, Harding VR, Ralphs JA, Jones SC, Dieudonné I, et al. Evaluation of a cognitive behavioural programme for rehabilitating patients with chronic pain. Br J Gen Pract. 1993;43(377):513-18.

[PMID:8312023]

6. Karjalainen K, Malmivaara A, van Tulder M, Roine R, Jauhiainen M, Hurri H, Koes B. Multidisciplinary biopsychosocial rehabilitation for subacute low back pain among working age adults. Cochrane Database Syst Rev. 2003;(2):CD002193. [PMID:12804427]

7. Flor H, Fydrich T, Turk DC. Efficacy of multidisciplinary pain treatment centers: A meta-analytic review. Pain. 1992;49(2):221-30. [PMID:1535122] http://dx.doi.org/10.1016/0304-3959(92)90145-2

8. Scascighini L, Sprott H. Chronic nonmalignant pain: A challenge for patients and clinicians. Nat Clin Pract Rheumatol. 2008;4(2):74-81. [PMID:18235536] http://dx.doi.org/10.1038/ncprheum0680

9. Schipper H, Clinch JJ, Olweny CL. Quality of life studies: Definitions and conceptual issues. In: Spilker B, editor. Quality of life and pharmacoeconomics in clinical trials. Philadelphia (PA): Lippincott-Raven; 1996. p. 11-23.

10. Cella DF. Measuring quality of life in palliative care. Semin Oncol. 1995;22(2 Suppl 3):73-81. [PMID:7537908]

11. Ware JE Jr, Sherbourne CD. The MOS 36-Item Short-Form Health Survey (SF-36). I. Conceptual framework and item selection. Med Care. 1992;30(6):473-83. [PMID:1593914] http://dx.doi.org/10.1097/00005650-199206000-00002

12. Chen TH, Li L, Kochen MM. A systematic review: How to choose appropriate health-related quality of life (HRQOL) measures in routine general practice? J Zhejiang Univ Sci B. 2005;6(9):936-40. [PMID:16130199] http://dx.doi.org/10.1631/jzus.2005.B0936 
13. Ware JE Jr. The status of health assessment 1994. Annu Rev Public Health. 1995;16:327-54. [PMID:7639876] http://dx.doi.org/10.1146/annurev.pu.16.050195.001551

14. Ware JE, Snow KK, Kosinski M, Gandek B. SF-36 Health Survey: Manual and interpretation guide. Boston (MA): New England Medical Center Hospital Health Institute; 1993.

15. Haley SM, Coster WJ, Binda-Sundberg K. Measuring physical disablement: The contextual challenge. Phys Ther. 1994;74(5):443-51. [PMID:8171106]

16. Townsend E. Enabling occupation: An occupational therapy perspective. Ottawa (Canada): Canadian Association of Occupational Therapists; 1997.

17. Cup EH, Scholte op Reimer WJ, Thijssen MC, van KuykMinis MA. Reliability and validity of the Canadian Occupational Performance Measure in stroke patients. Clin Rehabil. 2003;17(4):402-9. [PMID:12785249] http://dx.doi.org/10.1191/0269215503cr635oa

18. Clark NM, Janz NK, Dodge JA, Mosca L, Lin X, Long Q, Little RJ, Wheeler JR, Keteyian S, Liang J. The effect of patient choice of intervention on health outcomes. Contemp Clin Trials. 2008;29(5):679-86. [PMID:18515187] http://dx.doi.org/10.1016/j.cct.2008.04.002

19. Heyn L, Finset A, Eide H, Ruland CM. Effects of an interactive tailored patient assessment on patient-clinician communication in cancer care. Psychooncology. 2013;22(1): 89-96. [PMID:21919122]

http://dx.doi.org/10.1002/pon.2064

20. Law M, Baptiste S, Carswell A, McColl MA, Polatajko H, Pollock N. Canadian Occupational Performance Measure. Toronto (Canada): Canadian Association of Occupational Therapists; 2005.

21. Kjeken I, Slatkowsky-Christensen B, Kvien TK, Uhlig T. Norwegian version of the Canadian Occupational Performance Measure in patients with hand osteoarthritis: validity, responsiveness, and feasibility. Arthritis Rheum. 2004;51(5): 709-15. [PMID:15478169] http://dx.doi.org/10.1002/art.20522

22. McColl MA, Paterson M, Davies D, Doubt L, Law M. Validity and community utility of the Canadian Occupational Performance Measure. Can J Occup Ther. 2000;67(1): 22-30. [PMID:10695166] http://dx.doi.org/10.1177/000841740006700105

23. Persson E, Rivano-Fischer M, Eklund M. Evaluation of changes in occupational performance among patients in a pain management program. J Rehabil Med. 2004;36(2):85-91. [PMID:15180223] http://dx.doi.org/10.1080/16501970310019142

24. Spadaro A, Lubrano E, Massimiani MP, Gaia P, Perrotta FM, Parsons WJ, Ferrara N, Valesini G. Validity, responsiveness and feasibility of an Italian version of the Canadian Occupational Performance Measure for patients with ankylosing spondylitis. Clin Exp Rheumatol. 2010;28(2): 215-22. [PMID:20483043]

25. Wressle E, Lindstrand J, Neher M, Marcusson J, Henriksson C. The Canadian Occupational Performance Measure as an outcome measure and team tool in a day treatment programme. Disabil Rehabil. 2003;25(10):497-506.

[PMID:12745961]

http://dx.doi.org/10.1080/0963828031000090560

26. Carswell A, McColl MA, Baptiste S, Law M, Polatajko H, Pollock N. The Canadian Occupational Performance Measure: A research and clinical literature review. Can J Occup Ther. 2004;71(4):210-22. [PMID:15586853] http://dx.doi.org/10.1177/000841740407100406

27. Colquhoun H, Letts L, Law M, MacDermid J, Edwards M. Feasibility of the Canadian Occupational Performance Measure for routine use. Br J Occup Ther. 2010;73(2):48-54. http://dx.doi.org/10.4276/030802210X12658062793726

28. Boyer G, Hachey R, Mercier J. Perceptions of occupational performance and subjective quality of life in persons with severe mental illness. Occup Ther Ment Health. 2000;15: 1-15. http://dx.doi.org/10.1300/J004v15n02 01

29. Carpenter L, Baker GA, Tyldesley B. The use of the Canadian Occupational Performance Measure as an outcome of a pain management program. Can J Occup Ther. 2001; 68(1):16-22. [PMID:11233684] http://dx.doi.org/10.1177/000841740106800102

30. Chan CC, Lee TM. Validity of the Canadian Occupational Performance Measure. Occup Ther Int. 1997;4(3):231-49. http://dx.doi.org/10.1002/oti.58

31. Dedding C, Cardol M, Eyssen IC, Dekker J, Beelen A. Validity of the Canadian Occupational Performance Measure: A client-centred outcome measurement. Clin Rehabil. 2004;18(6):660-67. [PMID:15473118] http://dx.doi.org/10.1191/0269215504cr746oa

32. Law M, Darrah J, Pollock N, King G, Rosenbaum P, Russell D, Palisano R, Harris S, Armstrong R, Watt J. Familycentred functional therapy for children with cerebral palsy: An emerging practice model. Phys Occup Ther Pediatr. 1998;18:83-102.

33. van Meeteren NL, Strato IH, van Veldhoven NH, De Kleijn P, van den Berg HM, Helders PJ. The utility of the Dutch Arthritis Impact Measurement Scales 2 for assessing health status in individuals with haemophilia: A pilot study. Haemophilia. 2000;6(6):664-71. [PMID:11122393] http://dx.doi.org/10.1046/j.1365-2516.2000.00440.x

34. Ripat J, Etcheverry E, Cooper J, Tate RB. A comparison of the Canadian Occupational Performance Measure and the Health Assessment Questionnaire. Can J Occup Ther. 2001; 68(4):247-53. [PMID:11680919] http://dx.doi.org/10.1177/000841740106800408

35. Rochman DL, Ray SA, Kulich RJ, Mehta NR, Driscoll S. Validity and utility of the Canadian Occupational Performance 
Measure as an outcome measure in a craniofacial pain center. OTJR (Thorofare N J). 2008;28(1):4-11.

36. Veehof MM, Sleegers EJ, van Veldhoven NH, Schuurman AH, van Meeteren NL. Psychometric qualities of the Dutch language version of the Disabilities of the Arm, Shoulder, and Hand questionnaire (DASH-DLV). J Hand Ther. 2002; 15(4):347-54. [PMID:12449349] http://dx.doi.org/10.1016/S0894-1130(02)80006-0

37. Verkerk GJ, Wolf MJ, Louwers AM, Meester-Delver A, Nollet F. The reproducibility and validity of the Canadian Occupational Performance Measure in parents of children with disabilities. Clin Rehabil. 2006;20(11):980-88. [PMID:17065541] http://dx.doi.org/10.1177/0269215506070703

38. Walsh AD, Kelly JS, Johnson SP, Rajkumar S, Bennetts K. Performance problems of patients with chronic low-back pain and the measurement of patient-centered outcome. Spine (Phila Pa 1976). 2004;29(1):87-93. [PMID:14699282]

39. Chen YH, Rodger S, Polatjko H. Experiences with the COPM and client-centred practice in adult neurorehabilitation in Taiwan. Occup Ther Int. 2002;9(3):167-84. [PMID:12921096] http://dx.doi.org/10.1002/oti.163

40. Effing E, Dirx E, Sleegers EJ, Van Meeteren N. De responsiviteit van de COPM, ARA en SODA voor veranderingen in handvaardigheid bij plastisch-chirurgische handpatienten [The responsiveness of the COPM, ARA, and SODA to detect changes in hand skills of patients after plastic surgery]. Ned Tijd Ergo. 1999;27(3):109-16. Dutch.

41. Eyssen IC, Steultjens MP, Oud TA, Bolt EM, Maasdam A, Dekker J. Responsiveness of the Canadian occupational performance measure. J Rehabil Res Dev. 2011;48(5):517-28. [PMID:21674402] http://dx.doi.org/10.1682/JRRD.2010.06.0110

42. Wressle E, Samuelsson K, Henriksson C. Responsiveness of the Swedish version of the Canadian Occupational Performance Measure. Scand J Occup Ther. 1999;6(26):84-89.

43. Eyssen IC, Beelen A, Dedding C, Cardol M, Dekker J. The reproducibility of the Canadian Occupational Performance Measure. Clin Rehabil. 2005;19(8):888-94.

[PMID:16323388]

http://dx.doi.org/10.1191/0269215505cr883oa

44. Kjeken I, Dagfinrud H, Uhlig T, Mowinckel P, Kvien TK, Finset A. Reliability of the Canadian Occupational Performance Measure in patients with ankylosing spondylitis. J Rheumatol. 2005;32(8):1503-9. [PMID:16078326]

45. Pan AW, Chung L, Hsin-Hwei G. Reliability and validity of the Canadian Occupational Performance Measure for clients with psychiatric disorders in Taiwan. Occup Ther Int. 2003;10(4):269-77. [PMID:14647540]

http://dx.doi.org/10.1002/oti.190
46. Sewell L, Singh S. The Canadian Occupational Performance Measure: Is it a reliable measure in clients with chronic obstructive pulmonary disease? Br J Occup Ther. 2001;64:305-10.

47. de Vet HC, Terwee CB, Bouter LM. Clinimetrics and psychometrics: Two sides of the same coin. J Clin Epidemiol. 2003;56:1146-47. http://dx.doi.org/10.1016/j.jclinepi.2003.08.010

48. Jolles BM, Buchbinder R, Beaton DE. A study compared nine patient-specific indices for musculoskeletal disorders. J Clin Epidemiol. 2005;58(8):791-801. [PMID:16018914] http://dx.doi.org/10.1016/j.jclinepi.2005.01.012

49. Van Duijn HM, Niezen AA, Cardol M, Corder-Bartels IE, Verkerk GJ. De Nederlandse versie van de Canadian Occupational Performance Measure (COPM). Amsterdam (the Netherlands): Afdeling Ergotherapie, VU Universitair Medisch Centrum; 1999. Dutch.

50. Pollard CA. Preliminary validity study of the pain disability index. Percept Mot Skills. 1984;59(3):974.

[PMID:6240632]

http://dx.doi.org/10.2466/pms.1984.59.3.974

51. Hays RD, Sherbourne CD, Mazel RM. The RAND 36-Item Health Survey 1.0. Health Econ. 1993;2(3):217-27. [PMID:8275167] http://dx.doi.org/10.1002/hec.4730020305

52. Law M, Baptiste S, McColl M, Opzoomer A, Polatajko H, Pollock N. The Canadian Occupational Performance Measure: An outcome measure for occupational therapy. Can J Occup Ther. 1990;57(2):82-87. [PMID:10104738] http://dx.doi.org/10.1177/000841749005700207

53. Chibnall JT, Tait RC. The Pain Disability Index: Factor structure and normative data. Arch Phys Med Rehabil. 1994;75(10):1082-86. [PMID:7944912] http://dx.doi.org/10.1016/0003-9993(94)90082-5

54. Grönblad M, Järvinen E, Hurri H, Hupli M, Karaharju EO. Relationship of the Pain Disability Index (PDI) and the Oswestry Disability Questionnaire (ODQ) with three dynamic physical tests in a group of patients with chronic low-back and leg pain. Clin J Pain. 1994;10(3):197-203. [PMID:7833577] http://dx.doi.org/10.1097/00002508-199409000-00005

55. Tait RC, Pollard CA, Margolis RB, Duckro PN, Krause SJ. The Pain Disability Index: Psychometric and validity data. Arch Phys Med Rehabil. 1987;68(7):438-41.

[PMID:3606368]

56. Aaronson NK, Muller M, Cohen PD, Essink-Bot ML, Fekkes M, Sanderman R, Sprangers MA, te Velde A, Verrips E. Translation, validation, and norming of the Dutch language version of the SF-36 Health Survey in community and chronic disease populations. J Clin Epidemiol. 1998; 51(11):1055-68. [PMID:9817123] http://dx.doi.org/10.1016/S0895-4356(98)00097-3 
57. Wittink H, Turk DC, Carr DB, Sukiennik A, Rogers W. Comparison of the redundancy, reliability, and responsiveness to change among SF-36, Oswestry Disability Index, and Multidimensional Pain Inventory. Clin J Pain. 2004; 20(3):133-42. [PMID:15100588] http://dx.doi.org/10.1097/00002508-200405000-00002

58. Van der Zee K, Sanderman R. Het meten van de algemene gezondheidstoestand met de RAND-36: Een handleiding [Measuring general health with the RAND-36: A manual]. 2nd ed. Groningen (the Netherlands): Noordelijk Centrum voor Gezondheidsvraagstukken NCG; 2012. Dutch.

59. Terwee CB, Bot SD, de Boer MR, van der Windt DA, Knol DL, Dekker J, Bouter LM, de Vet HC. Quality criteria were proposed for measurement properties of health status questionnaires. J Clin Epidemiol. 2007;60(1):34-42.

[PMID:17161752]

http://dx.doi.org/10.1016/j.jclinepi.2006.03.012

60. Mokkink LB, Terwee CB, Knol DL, Stratford PW, Alonso J, Patrick DL, Bouter LM, de Vet HC. The COSMIN checklist for evaluating the methodological quality of studies on measurement properties: A clarification of its content. BMC Med Res Methodol. 2010;10:22. [PMID:20298572] http://dx.doi.org/10.1186/1471-2288-10-22

61. Mokkink LB, Terwee CB, Patrick DL, Alonso J, Stratford PW, Knol DL, Bouter LM, de Vet HC. The COSMIN checklist for assessing the methodological quality of studies on measurement properties of health status measurement instruments: An international Delphi study. Qual Life Res. 2010;19(4):539-49. [PMID:20169472] http://dx.doi.org/10.1007/s11136-010-9606-8

62. Cohen J. Statistical power analysis for the behavioral sciences. 2nd ed. Hillsdale (NJ): Lawrence Erlbaum Associates; 1988.

63. Post MW, van Leeuwen CM, van Koppenhagen CF, de Groot S. Validity of the Life Satisfaction questions, the Life Satisfaction Questionnaire, and the Satisfaction With Life Scale in persons with spinal cord injury. Arch Phys Med
Rehabil. 2012;93(10):1832-37. [PMID:22484088]

http://dx.doi.org/10.1016/j.apmr.2012.03.025

64. World Health Organization. International Classification of Functioning, Disability and Health: ICF. Geneva (Switzerland): World Health Organization; 2001.

65. de Vet HC, Terwee CB, Mokkink LB, Knol DL. Measurement in medicine: A practical guide. Cambridge (United Kingdom): Cambridge University Press; 2011.

66. Brockow T, Cieza A, Kuhlow H, Sigl T, Franke T, Harder M, Stucki G. Identifying the concepts contained in outcome measures of clinical trials on musculoskeletal disorders and chronic widespread pain using the International Classification of Functioning, Disability and Health as a reference. J Rehabil Med. 2004;(44 Suppl):30-36. [PMID:15370745]

67. Hieblinger R, Coenen M, Stucki G, Winkelmann A, Cieza A. Identification of essential elements of functioning in chronic widespread pain based on a statistical approach. Am J Phys Med Rehabil. 2011;90(12):979-91. [PMID:22019964] http://dx.doi.org/10.1097/PHM.0b013e318228c89c

68. Streiner DL, Norman GR. Health measurement scales: A practical guide to their development and use. 3rd ed. Oxford (United Kingdom): Oxford University Press; 2003.

Submitted for publication December 6, 2012. Accepted in revised form December 23, 2013.

This article and any supplementary material should be cited as follows:

Nieuwenhuizen MG, de Groot S, Janssen TW, van der Maas LC, Beckerman H. Canadian Occupational Performance Measure performance scale: Validity and responsiveness in chronic pain. J Rehabil Res Dev. 2014;51(5): 727-46.

http://dx.doi.org/10.1682/JRRD.2012.12.0221

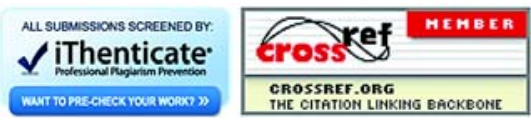

